\title{
QUÍMICA E ARTE: UMA PROPOSTA DE DESENVOLVIMENTO DE UM PROJETO A PARTIR DA METODOLOGIA ABP
}

Cárita Dias Ramos Nascimento

Esteban Lopez Moreno

\section{Introdução}

A junção entre Química e Arte inicialmente pode parecer distante, mas de um modo geral ao analisá-las é possível constatar como as diferenças e semelhanças entre ambas podem surtir efeitos positivos no ensino de Química. Pietrocola (2004) relata que:

\begin{abstract}
"Representar e explicar são aspectos bem marcantes das artes e das ciências. No entanto, essas diferenças não nos autorizam a colocar arte e ciências em domínios opostos do fazer humano, como poderia sugerir essa explanação preliminar. Pois a ciência também representa e a arte, a sua maneira, pode explicar" (PIETROCOLA, 2004, p.3).
\end{abstract}

Como pesquisa do mestrado da presente professora-pesquisadora investigou como o uso de atividades artísticas relacionadas ao ensino de Química podem contribuir para a motivação do estudante. Diante disso, foi 
proposto como produto de pesquisa a elaboração de um encarte para professores e alunos, do ensino básico, intitulado "Química e Arte: Ensino além da sala de aula" com estratégias de como desenvolver um projeto, a partir da metodologia Aprendizagem Baseada em Projetos (ABP), reproduzindo-se uma versão da Festa dos Elementos Químicos, além de um blog exposto como recurso didático e de fácil acesso para ambos os públicos. Para isto, a turma que desenvolveu o projeto sob a orientação da professora regente, seguiu etapas fundamentais que serão descritas posteriormente. $\mathrm{O}$ encarte tem a finalidade de possibilitar que outros discentes e docentes possam realizar projetos semelhantes e assim possam notar que a junção entre Química e Arte pode ser um caminho de descobertas, reflexões, criatividade e ludicidade no ensino. $\mathrm{O}$ objetivo desse texto é apresentar o caminho percorrido na construção do produto de pesquisa de dissertação do mestrado e analisar a participação dos estudantes no vídeo e roteiro produzidos no desenvolvimento do projeto.

\section{Aprendizagem Baseada em Projetos (ABP)}

A Aprendizagem Baseada em Projetos, segundo Masson et al. (2012), explora a relevância da experiência prévia e da participação ativa como aspectos fundamentais para a motivação e obtenção de conhecimento, encorajando o estudante a trabalhar em equipe, a ouvir opiniões, a assumir um papel ativo e consciente da aprendiza- 
gem. Esta metodologia de ensino foi proposta primeiramente por Dewey por volta da década de 30, na perspectiva da Escola Nova, em que o filósofo propôs a necessidade de efetivar a disposição globalizada e atualizada dos conhecimentos e das pesquisas trabalhadas no ambiente escolar (BEHRENS e JOSÉ, 2001). Dewey (1976) ressalta a importância de:

\begin{abstract}
“[...] escolher as atividades suscetíveis de produzir a organização social, em que todos os indivíduos tenham a oportunidade de algo contribuir e em que o principal elemento de controle esteja nas próprias atividades por todos partilhadas" (DEWEY, 1976, p. 69)
\end{abstract}

Uma transformação drástica no papel do docente, na Aprendizagem Baseada em Projetos, refere-se a sua função de não colocar-se como o transmissor do saber, passando a ser um instigador e parceiro do discente na descoberta dos conhecimentos. Deste modo, na construção da aprendizagem motiva-se o estudante a solucionar dificuldades encontradas no desenvolvimento de um projeto (MASSON, et al., 2012).

O Quadro 1 expõe as diferenças entre as categorias relacionadas ao Ensino por Projetos e a Aprendizagem por Projetos. Neste caso, observa-se como é escolhido o tema, o contexto utilizado na execução do projeto, a quem o projeto satisfaz, como são tomadas as decisões para a 
sua execução, como são estipuladas as atividades de desenvolvimento do projeto, o paradigma selecionado, o papel do docente e o papel do estudante. Nota-se como a execução de um projeto exige tanto do discente quanto do docente, um trabalho construtivo no processo de ensinoaprendizagem.

Quadro 1 - Indicativos de Ensino de Aprendizagem

\begin{tabular}{|c|c|c|}
\hline Questões & Ensino por projetos & $\begin{array}{c}\text { Aprendizagem por pro- } \\
\text { jetos }\end{array}$ \\
\hline $\begin{array}{l}\text { Quem escolhe o } \\
\text { tema? }\end{array}$ & $\begin{array}{l}\text { Professores, coordena- } \\
\text { ção pedagógica. }\end{array}$ & $\begin{array}{l}\text { Alunos e professores } \\
\text { individualmente e, ao } \\
\text { mesmo tempo, em coo- } \\
\text { peração. }\end{array}$ \\
\hline Qual é o contexto? & $\begin{array}{l}\text { Arbitrado por critérios } \\
\text { externos e formais. }\end{array}$ & $\begin{array}{l}\text { Realidade da vida do } \\
\text { aluno. }\end{array}$ \\
\hline A quem satisfaz? & $\begin{array}{l}\text { Arbítrio da sequência } \\
\text { de conteúdos do } \\
\text { currículo. }\end{array}$ & $\begin{array}{l}\text { Curiosidade, desejo, } \\
\text { vontade do aprendiz. }\end{array}$ \\
\hline $\begin{array}{l}\text { Como são tomadas } \\
\text { as decisões? }\end{array}$ & Hierárquicas & Heterárquicas \\
\hline $\begin{array}{l}\text { Como são definidas } \\
\text { as regras, direções e } \\
\text { atividades? }\end{array}$ & $\begin{array}{l}\text { Impostas pelo sistema } \\
\text { e cumpre determina- } \\
\text { ções sem optar. }\end{array}$ & $\begin{array}{c}\text { Elaboradas pelo grupo, } \\
\text { consenso de alunos e } \\
\text { professores. }\end{array}$ \\
\hline Qual o paradigma? & $\begin{array}{l}\text { Transmissão do co- } \\
\text { nhecimento. }\end{array}$ & $\begin{array}{l}\text { Construção do conheci- } \\
\text { mento. }\end{array}$ \\
\hline $\begin{array}{c}\text { Qual é o papel do } \\
\text { professor? }\end{array}$ & Agente & $\begin{array}{l}\text { Problematiza- } \\
\text { dor/orientador. }\end{array}$ \\
\hline $\begin{array}{c}\text { Qual é o papel do } \\
\text { aluno? }\end{array}$ & Receptivo & Agente \\
\hline
\end{tabular}

Fonte: FAGUNDES et al., 2008 apud MASSON, et al., 2012 
Leite (1994) expõe que no trabalho desenvolvido em uma Aprendizagem Baseada em Projetos (ABP) abrange características como: atividade intencional, a responsabilidade e a autonomia dos estudantes são fundamentais, a autenticidade deve fazer parte do projeto, o projeto envolve a resolução de problemas e o projeto percorre várias fases. Para desenvolver o projeto é necessário: "escolher o objetivo central, formulação dos problemas, planejamento, execução, avaliação, e divulgação dos trabalhos" (LEITE, 1994, p. 2). Isso mostra como em sua efetivação exige-se um envolvimento por parte do docente e dos estudantes a fim de que cada uma dessas fases seja contemplada.

Assim, os projetos de trabalho não se inserem apenas numa proposta de renovação de atividades - tornando-as mais criativas e sim numa mudança de postura, o que exige um repensar da prática pedagógica e das teorias que a estão informando. Entendida nessa perspectiva, a Pedagogia de Projetos é um caminho para transformar o espaço escolar em um espaço aberto à construção de aprendizagens significativas para todos que dele participam (LEITE, 1994, p.7).

\section{Interdisciplinaridade entre a Química e a Arte}

Relacionar a Química e a Arte pode intensificar a curiosidade e a imaginação do estudante, possibilitando 
um dinamismo entre os assuntos abordados em aula, permitindo que este perceba como as diferentes abordagens podem desenvolver um significado e contribuir assim para o ensino e aprendizagem da Química (COSTA, 2019).

Costa (2019) salienta que a utilização da arte possibilita que o educando enxergue o mundo Químico como parte de seu cotidiano, e não como algo fora de sua vida, em que o docente ao atuar como mediador no processo de ensino-aprendizagem permite assim que este torne-se mais atrativo.

Pietrocola (2004) expõe que a representação e a explicação são características marcantes das Ciências e das Artes e que mesmo ambas diferenciando-se em seus métodos, estas procuram a universalidade. Na Arte não há incumbência com a forma de representar, pelos participantes, onde cada artista tem liberdade no ato da criação. A Ciência, no entanto, segue conduzida pela coerência que não restringe-se ao próprio cientista, abrangendo a comunidade de especialistas ao qual pertence.

A aprendizagem da Ciências deve permear a criação científica ocorrendo de maneira efetiva através de uma participação ativa do estudante. Diante disso, quando a aula de Ciências adquire um espaço para reviver emoções associadas a criação produz no no aluno o an- 
seio em conhecer os assuntos e não apenas a abordá-lo de maneira metódica (PIETROCOLA, 2004).

A habilidade na produção e organização das ideias sustenta o conhecimento científico e na Arte, assim como nas Ciências, firmam-se na liberdade de criação. A imaginação permite que o cientista represente o mundo por meio das concepções. Outro fator relacionado à imaginação é o prazer oportunizado pelas criações. Assim, as atividades criativas nas duas disciplinas podem ocorrer de forma divertida e prazerosa (PIETROCOLA, 2004).

"A escola se imbui da missão de transmitir às novas gerações valores, atitudes, conhecimentos e demais elementos da cultura humana. Nessa tarefa, muitas vezes relega a criatividade e a imaginação ao aspecto meramente motivacional das atividades, atribuindo ao lúdico unicamente a capacidade de entreter. Em geral, separa-se as atividades de raciocínio daquelas imaginativas, como se tratassem de áreas desconexas do pensamento. Por um duplo preconceito, não atribuem ao raciocínio a possibilidade de criar, nem à imaginação de organizar e moldar representações sobre o mundo" (PIETROCOLA, 2004, p. 11-12).

A completividade entre as Artes e as Ciências proporciona saberes que podem ser conectados, como por exemplo, na procura por explicações dos eventos e o modo de comunicá-los, como também no apontamento das percepções e sensações da humanidade, diante do 
mundo e da sociedade (SÁ e FILHO, 2016). A Ciência, neste âmbito, passa a ser percebida no sentido de contribuir para que o indivíduo compreenda, intervenha e envolva-se com a sociedade. A Arte, então, completa essa formação impulsionando a sensibilidade e tornando as diferenças prazerosas e proveitosas (ROCHA; JUNIOR; NEVES, 2018).

Diante disso, expõe-se que a aprendizagem das Ciências, em especial da Química, deve ser um espaço para reviver as emoções ou sentimentos vinculados à emoção. Isso, porque muito das rejeições à disciplina, deve-se ao fato das escolas substituírem o fato da criação por aulas de memorização. Logo, a ligação entre as disciplinas, permite que o estudante exercite as percepções e os sentidos, por meio da criatividade e da imaginação e se torne um sujeito ativo (PIETROCOLA, 2004).

\section{A utilização de audiovisuais no ensino de Química}

A produção de audiovisuais é um desafio ainda a ser superado no ensino, apesar da inserção da tecnologia apresentar-se cada vez mais frequente no cotidiano dos estudantes. Os materiais audiovisuais no ambiente escolar promovem ações de interesse diferentes em relação ao ensino tradicional, totalmente expositivo, possibilitando o desenvolvimento de aspectos emotivos, imaginários e uma percepção diferenciada do ensino (PIRES, 2010). 
Paim (2006) expõe que na produção de um material audiovisual é necessário seguir algumas etapas no qual serão fundamentais em sua execução, tais como: a escolha de um assunto específico, com uso de referências fundamentadas que podem ser por meio de livros, jornais, entrevista, entre outros. A etapa seguinte refere-se a elaboração de um roteiro, seguido de gravação e edição. A última etapa refere-se a exposição do vídeo para a turma e uma discussão sobre o resultado obtido e a intenção inicial da produção. O docente nessa última etapa deve atuar como mediador na discussão entre os pontos positivos negativos na execução do material produzido.

Para o professor ao atuar como mediador é fundamental que utilize a criatividade, bom senso, habilidade e sua experiência a fim de que perceba em qual situação é a mais adequada para o uso do vídeo (SILVA, et al., 2012). A sua utilização deve ser de maneira planejada, condizente com a temática proposta para a aula e promovendo no educando a necessidade de exploração e envolvimento com a disciplina. Sua mera utilização, sem um objetivo definido, pode gerar dúvidas e insignificações quanto ao ensino e a aprendizagem. Isto porque,

"uma atividade em vídeo pode exercer funções bastante diversificadas no processo de ensino-aprendizagem como: informativa, motivadora, expressiva, avaliativa, conceitual" (SILVA, et al, 2012, p. 191). 
Almeida, Castro e Cavalcanti (2014) salientam que um vídeo escolhido de maneira coerente pode fazer com o que o discente explore sua curiosidade, quanto ao conteúdo ou ao próprio vídeo. Nesse caso, a curiosidade é um caminho que pode gerar diferentes reflexões e surgir em discussões interessantes. Promovendo na turma e no docente a possibilidade de tratar as diferentes temáticas de modo simultâneo.

\section{Metodologia}

A metodologia utilizada para o desenvolvimento do projeto refere-se a ABP (Aprendizagem Baseada em Projetos). No encarte "Química e Arte: Ensino além da sala de aula" é apresentado as principais etapas para a efetivação deste, além da produção do blog² intitulado "A Química é uma festa” no qual expõe todas as etapas do projeto e dispõe do encarte desenvolvido.

O encarte foi dividido em 3 capítulos, no qual o capítulo 1 refere-se a definição do produto e como este pode ser apresentado ao público. O capítulo 2 expõe su-

\footnotetext{
${ }^{1} \mathrm{O}$ encarte "Química e Arte: Ensino além da sala de aula" encontrase disponível no domínio público, no endereço: https://aquimicaeumafesta.blogspot.com/2020/o8/encarte-paraproducao-de-um-projeto.html

${ }^{2}$ O blog "A Química é uma festa" encontra-se disponível no domínio público, no endereço: https://aquimicaeumafesta.blogspot.com/
} 
gestões ao professor de como desenvolver um projeto semelhante com suas turmas, apresentando motivações para a execução do projeto e suas respectivas etapas. Nesta seção são apresentados indicativos de como o docente pode iniciar seu projeto e as tarefas que os alunos devem seguir. O público-alvo, a duração das aulas, os recursos utilizados, as disciplinas abordadas, as habilidades desenvolvidas nos estudantes, a metodologia utilizada, a duração e o editor do vídeo e um exemplo de avaliação são expostos neste tópico. O capítulo 3 expõe as orientações de como utilizar o blog. A Figura 1 apresenta a página inicial do blog.

Figura 1 - Página inicial do blog

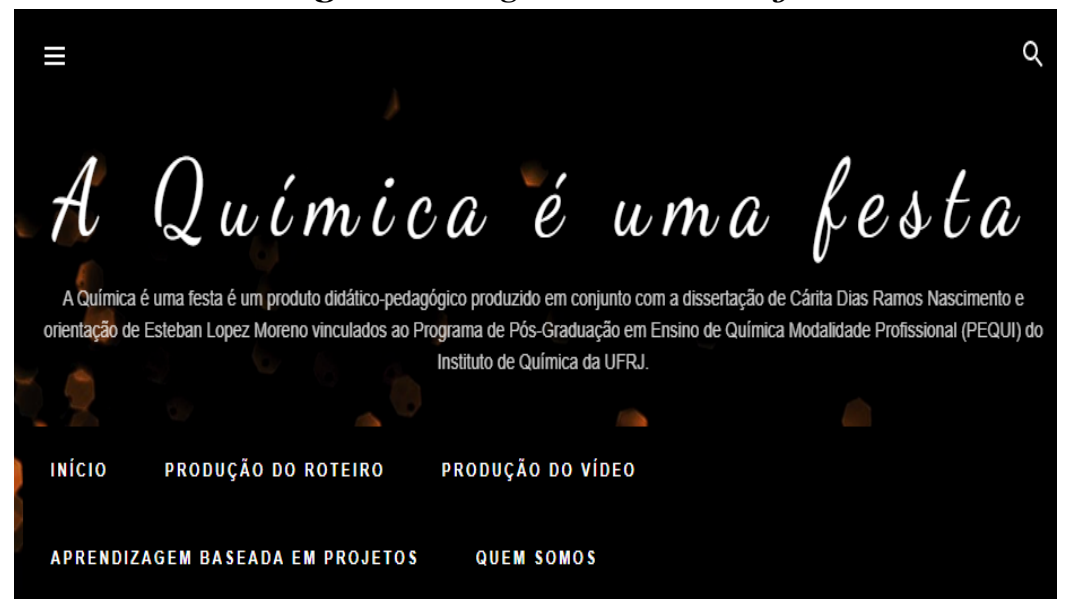

Fonte: autora

Além dos capítulos apresentados anteriormente também foram desenvolvidos os apêndices: apêndice A - 
Roteiro para elaboração do projeto, que consiste em explicitar inicialmente aos estudantes a proposta de execução da atividade, o apêndice B - Termo de autorização de participação do menor e uso de imagem é um exemplo de um termo que pode ser utilizado e o Apêndice C - Roteiro: A festa dos elementos químicos é um modelo de um roteiro desenvolvido pela turma que executou o projeto na pesquisa de dissertação.

O blog foi subdivido nos menus: Início, Produção do roteiro, Produção do vídeo e Aprendizagem Baseada em Projetos. O menu Início dispõe da definição da Festa dos Elementos Químicos e sua relação com o uso de metodologias ativas. $\mathrm{O}$ menu Produção do roteiro além de apresentar dicas de como a turma e o docente podem desenvolvê-lo, há o relato de experiência sobre o roteiro elaborado pela turma do projeto. O menu Produção do vídeo introduz as etapas de execução do vídeo e retrata orientações sobre esta fase no projeto ABP (Aprendizagem Baseada em Projetos). O menu Aprendizagem Baseada em Projeto expõe de maneira sucinta a definição e objetivo da ABP e um relato de como tal metodologia influenciou no desenvolvimento do projeto. Cada menu do blog pode ser acessado através dos endereços eletrônicos disponíveis no quadro 2. 
Quadro 2- Orientações de utilização do blog

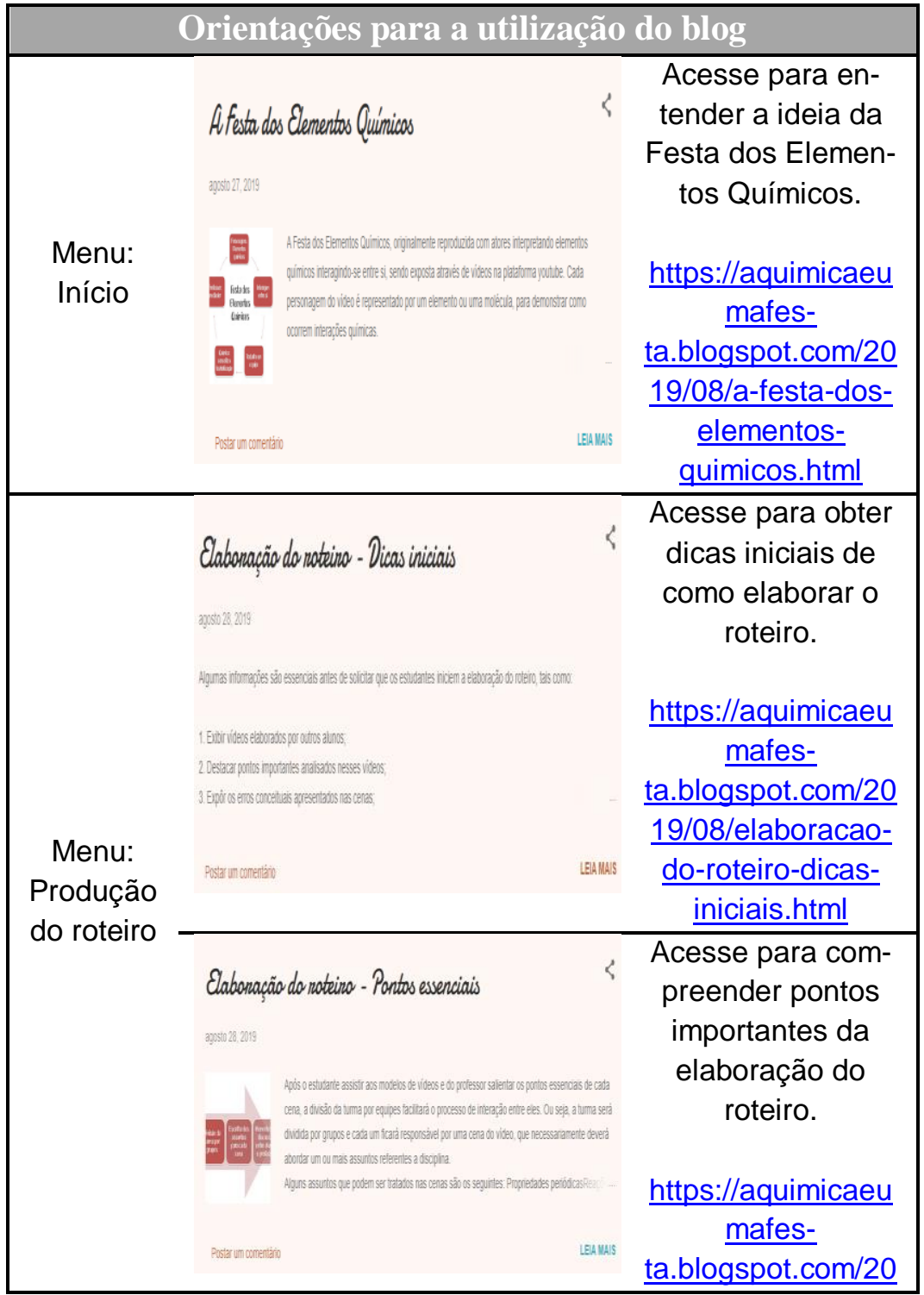




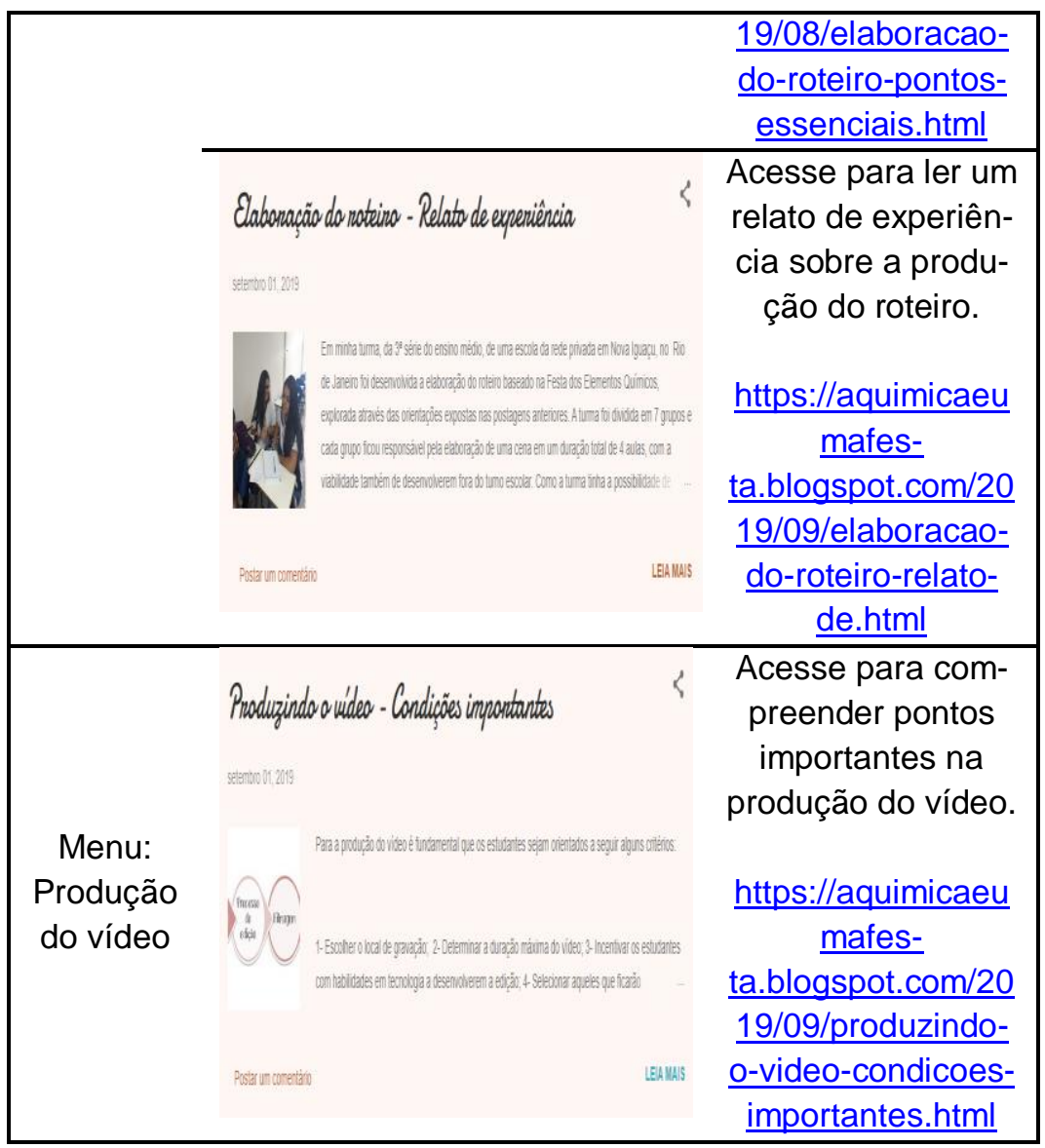




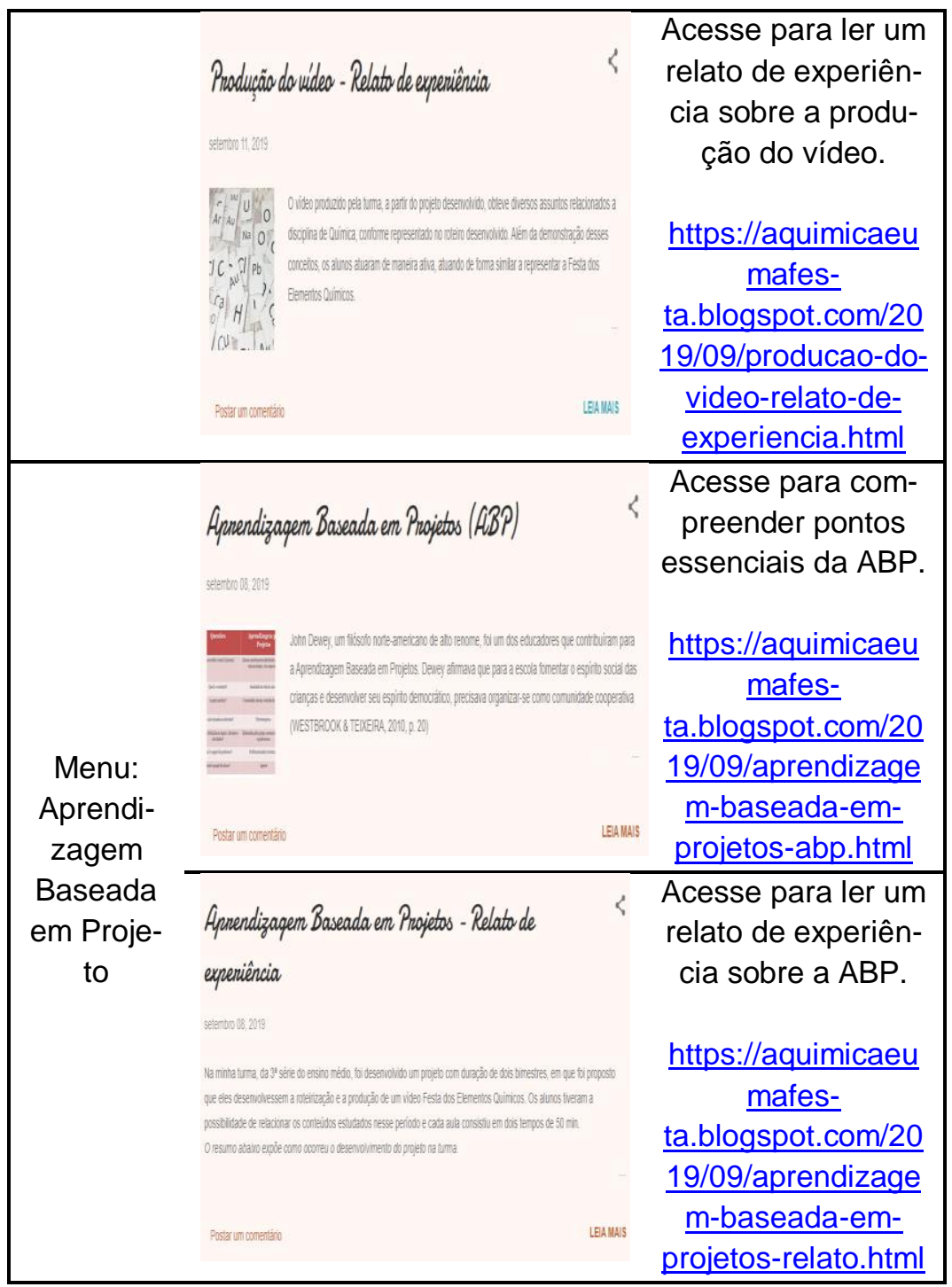

Fonte: autora 


\section{Resultados e discussões}

O roteiro elaborado pelos estudantes está presente no encarte e foi dividido em 7 cenas, em que cada uma destas expõe um dos conteúdos presentes na tabela 1. Em cada cena foram explicitados os principais assuntos, além da representação poética por meio da atuação dos estudantes. O que pode ser notado, por docentes, como um obstáculo epistemológico. No entanto, foi discutido com os estudantes sobre como a encenação não era de fato a formação, por exemplo, de uma ligação química, mas apenas uma representação artística sobre a exposição de uma temática.

Os assuntos do roteiro foram selecionados pelos estudantes, já que estes tinham a possibilidade de abordar qualquer um dos assuntos expostos no cronograma de conteúdos da escola, durante aquela série. Na escola em questão, na $3^{\mathrm{a}}$ série do ensino médio, os estudantes revisam todo o conteúdo de Química apresentado nos anos anteriores, logo a possibilidade de abordar os mais variados assuntos permitiu que estes explorassem os assuntos de sua escolha. 
Tabela 1 - Conteúdos presentes nas cenas do roteiro

\begin{tabular}{|c|c|}
\hline Cenas & Conteúdos \\
\hline 1 & Representação da ligação covalente \\
\hline 2 & Representação dos metais e ametais no cotidiano \\
\hline 3 & Representação dos gases nobres e dos platinóides \\
\hline 4 & Representação dos elementos artificiais \\
\hline 5 & $\begin{array}{l}\text { Representação dos elementos radioativos e de rea- } \\
\text { ções químicas }\end{array}$ \\
\hline 6 & Representação das ligações químicas \\
\hline 7 & Representação dos metais, ametais e gases nobres \\
\hline
\end{tabular}

Fonte: autora

Cabe salientar, que na produção do roteiro a professora-pesquisadora mediou o processo da escrita apontando os erros conceituais e/ou gramaticais. Observou-se que para produzir o roteiro os estudantes tiveram as seguintes dificuldades: repetição de ideias, a constância em utilizar os mesmos elementos na representação de cada cena e o impasse em colocar no papel as suas ideias. Esses fatores foram discutidos com os estudantes e estes foram estimulados a superar esses desafios, expondo-se que "os alunos precisam sentir-se seguros para arriscarse e errar e aprender com aqueles erros" (STUMPENHORST, 2018, p. 29).

A Tabela 2 apresenta as perguntas relativas ao questionário apresentado aos alunos após o desenvolvi- 
mento do projeto, contendo afirmativas que deveriam ser respondidas após a visualização do vídeo e que estavam baseadas na escala Likert, conforme a descrição: 1: Discordo totalmente, 2: Discordo, 3: Não discordo, nem concordo, 4: Concordo e 5: Concordo totalmente.

Tabela 2 - Resultados do questionário

\begin{tabular}{|c|c|c|c|c|c|}
\hline $\begin{array}{l}\text { Respostas obtidas do } \\
\text { questionário }\end{array}$ & 1 & 2 & 3 & 4 & 5 \\
\hline $\begin{array}{l}\text { 1- Depois de assistir } \\
\text { ao vídeo, a legenda } \\
\text { ajudou a compreender } \\
\text { as encenações. }\end{array}$ & $\begin{array}{c}1 \\
(2,9 \%)\end{array}$ & $\begin{array}{c}- \\
(0 \%)\end{array}$ & $\begin{array}{c}8 \\
(22,9 \%)\end{array}$ & $\begin{array}{c}4 \\
(11,4 \%)\end{array}$ & $\begin{array}{c}24 \\
(62,9 \%)\end{array}$ \\
\hline $\begin{array}{l}\text { 2- Você passou a } \\
\text { perceber a disciplina } \\
\text { de Química de manei- } \\
\text { ra diferenciada, de- } \\
\text { pois de assistir ao } \\
\text { vídeo. }\end{array}$ & $\begin{array}{l}- \\
(0 \%)\end{array}$ & $\begin{array}{c}2 \\
(5,7 \%)\end{array}$ & $\begin{array}{c}9 \\
(25,7 \%)\end{array}$ & $\begin{array}{c}14 \\
(37,1 \%)\end{array}$ & $\begin{array}{c}12 \\
(31,4 \%)\end{array}$ \\
\hline $\begin{array}{l}\text { 3- Vídeos como esses } \\
\text { podem estimular a } \\
\text { curiosidade por algum } \\
\text { assunto de Química. }\end{array}$ & $\begin{array}{l}- \\
(0 \%)\end{array}$ & $\begin{array}{c}- \\
(0 \%)\end{array}$ & $\begin{array}{c}2 \\
(5,7 \%)\end{array}$ & $\begin{array}{c}7 \\
(20 \%)\end{array}$ & $\begin{array}{c}28 \\
(74,3 \%)\end{array}$ \\
\hline $\begin{array}{l}\text { 4- Você gostaria que } \\
\text { seu(sua) professor(a) }\end{array}$ & $\begin{array}{c}2 \\
(5,7 \%)\end{array}$ & $\begin{array}{c}4 \\
(11,4 \%\end{array}$ & $\begin{array}{c}2 \\
(5,7 \%)\end{array}$ & $\begin{array}{c}2 \\
(5,7 \%)\end{array}$ & $\begin{array}{c}27 \\
(71,4 \%)\end{array}$ \\
\hline $\begin{array}{l}\text { desenvolvesse uma } \\
\text { atividade semelhante, } \\
\text { em suas aulas de } \\
\text { Química. }\end{array}$ & & ) & & & \\
\hline $\begin{array}{l}\text { 5- Interesse pela } \\
\text { disciplina Química } \\
\text { equivale a ... }\end{array}$ & $\begin{array}{c}3 \\
(8,1 \%)\end{array}$ & $\begin{array}{c}4 \\
(10,8 \% \\
\quad)\end{array}$ & $\begin{array}{c}15 \\
(40,5 \%)\end{array}$ & $\begin{array}{c}11 \\
(29,7 \%)\end{array}$ & $\begin{array}{c}4 \\
(10,8 \%)\end{array}$ \\
\hline $\begin{array}{r}\text { Marque 1:Discordo } \\
\text { concordo, } \\
\text { Fonte }\end{array}$ & talm & 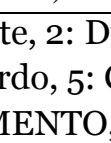 & 100 & o disc & \\
\hline
\end{tabular}


Analisando as afirmativas 1 a 5 observam-se os seguintes resultados:

Afirmativa 1: Os resultados mais expressivos quanto à essa afirmativa concentraram-se em concordar totalmente, com uma porcentagem de $62,9 \%$ demonstrando como a legenda foi um fator importante na compreensão das encenações.

Afirmativa 2: Os resultados mostram que a maior parte dos estudantes concordaram $(37,1 \%)$ e concordaram totalmente $(31,4 \%)$ sobre perceber a Química de maneira diferenciada após assistirem o vídeo. Um resultado objetivado, já que o vídeo apresentava também essa finalidade de mostrar que a Química pode ser associada a atividades artísticas produzindo uma visão diferenciada e benéfica entre ambas as disciplinas, comprovando que "toda a atividade criativa, seja na ciência na arte ou em qualquer outro campo de ação, é divertida e prazerosa (PIETROCOLA, 2004, p. 10).

Afirmativa 3: Ao analisar tal afirmativa, observa-se que $74,3 \%$ concordam totalmente que vídeos como o apresentado estimulam a curiosidade. Demonstrando satisfatoriamente como a curiosidade é um fator importante no estudo de variados assuntos de Química. Aliado a isso, Pietrocola (2004) expõe que: 
"As atividades científicas tornam-se interessantes e instigadoras quando são capazes de excitar nossa curiosidade. Através da imaginação, o pensamento passa a apreender o desconhecido buscando uma explicação para os enigmas. A curiosidade serve de fio condutor para as atividades, que de outra forma passam a ser burocráticas e exercidas com o propósito de cumprir obrigações" (PIETROCOLA, 2004, p. 12).

Afirmativa 4: $71,4 \%$ dos resultados mostraram que os estudantes concordaram totalmente no anseio de que o docente de Química realizasse atividades semelhantes a apresentada no projeto. O que leva a perceber que na Aprendizagem Baseada em Projetos, o professor ao produzir possibilidades para analisar os recursos permite que o aluno aprenda a aprender, assim como a organizar e desenvolver o próprio conhecimento (LEITE, 1994). Quando o discente sente a necessidade de explorar outras metodologias e surge a oportunidade do docente executálas, promove-se assim uma nova percepção sobre a disciplina.

"A verdadeira experiência educativa envolve, acima de tudo, continuidade e interação entre quem aprende e o que é aprendido" (DEWEY, 1976, p. 12). Tal fala exprime a relevância do educador em executar atividades, tais como esta, que possibilitem o educando interagir com a disciplina de modo criativo a despertar a sua 
curiosidade, não limitando sua capacidade de produzir e compartilhar os diversos assuntos.

Afirmativa 5: Essa afirmativa teve a finalidade de avaliar o grau de interesse pela disciplina de Química, obtendo-se os resultados mais expressivos entre nem concordar, nem discordar, com 40,5\% e concordar com 29,1\%. Chassot (2018) relata que a rejeição com relação a Química deve-se ao fato do seu ensino não ser útil e nem prazeroso. O que pode ser um fator que desencadeia o desestímulo na compreensão dos diversos assuntos diante da disciplina. Cabe ao professor, nesse caso, utilizar as ferramentas e metodologias essenciais no ensino e na aprendizagem dos diferentes assuntos, estimulando os estudantes a explorarem esses mecanismos de forma didática.

Outro aspecto a ser analisado refere-se a produção do vídeo, no qual está exposto no encarte e no blog no menu "Produção do vídeo". Este teve duração de 5 min $56 \mathrm{~s}$ e após a sua análise nota-se como as cenas estabeleceram, na maior parte das cenas, relação com o roteiro. Observase que os estudantes mostraram-se envolvidos nas encenações, atuando de forma didática. Cabe salientar, que a professora-pesquisadora, esteve presente no dia da gravação e que os estudantes puderam consultá-la sempre que necessitavam e que esta ao atuar como mediadora, possibilitou que o educando reconhecesse as distintas linguagens e beneficiou-se dos recursos tecnológicos de 
maneira lúdica e satisfatória (ALMEIDA, CASTRO e CAVALCANTI, 2014). A tabela 3 expõe a duração de cada cena e a descrição dos eventos ocorridos no vídeo.

Tabela 3 - Descrição dos eventos no vídeo.

\begin{tabular}{|c|c|c|}
\hline Minutagem & Cenas & Descrição dos eventos \\
\hline 00:00 a 00:37 & 1 & $\begin{array}{l}\text { Representação do elemento } \\
\text { oxigênio e da molécula } \mathrm{H}_{2} \mathrm{O} \text {. }\end{array}$ \\
\hline 00:38 a 01:34 & 2 & $\begin{array}{l}\text { Representação dos metais e } \\
\text { dos ametais. }\end{array}$ \\
\hline 01:35 a 02:04 & 3 & $\begin{array}{l}\text { Representação dos gases } \\
\text { nobres e dos platinóides. }\end{array}$ \\
\hline 02:05 a 02:25 & 4 & $\begin{array}{l}\text { Representação dos elemen- } \\
\text { tos artificiais. }\end{array}$ \\
\hline $02: 26$ a $03: 20$ & 5 & $\begin{array}{l}\text { Representação da ligação } \\
\text { covalente, de um elemento } \\
\text { radioativo e de uma reação } \\
\text { química violenta. }\end{array}$ \\
\hline $03: 21$ a $04: 36$ & 6 & $\begin{array}{l}\text { Representação da ligação } \\
\text { iônica e da metálica. }\end{array}$ \\
\hline $04: 37$ a $05: 56$ & 7 & $\begin{array}{l}\text { Finalização do vídeo, com a } \\
\text { saída dos elementos da festa. }\end{array}$ \\
\hline
\end{tabular}

Fonte: NASCIMENTO, 2020 (adaptada)

As legendas expressas no vídeo explicitaram de modo resumido os conceitos artísticos relacionados aos conceitos químicos. Em todas as cenas dos vídeos os estudantes utilizaram placas para representar cada um dos elementos químicos, e quando estes interagiam, eles representavam as moléculas, como por exemplo a $\mathrm{H}_{2} \mathrm{O}$ ex- 
posta na cena 1 , de modo poético e artístico. Os metais e os ametais da cena 2 foram expostos com por meio de ilustrações do cotidiano, como por exemplo, o elemento cálcio foi representado por um aluno segurando um osso, o elemento chumbo por um peso de academia, o elemento cobre por um fio. Nesse momento os estudantes expuseram de maneira criativa e didática as ideias do roteiro. "Aumentar as habilidades do aluno na tomada de decisão, na criatividade e na colaboração" (STUMPENHORST, 2018, p. 118) permite que o ensino torne-se atrativo e que o aluno interaja de modo significativo, seja por meio da união entre Artes e Química, ou por meio de um recurso tecnológico, como a produção de um vídeo.

Na cena 3 em que há a representação dos gases nobres, os alunos vestiram-se como reis para expressar pessoas da nobreza. Nessa cena ficou explicitado o uso da criatividade e da apresentação artística para expor um conceito científico, no entanto, sem expor sua definição de maneira direta. A cena 4 teve pouca relação com o que foi descrito no roteiro, em que os alunos expressaram que iriam utilizar perucas, maquiagens e roupas imitando “pessoas tidas como artificiais". Já no vídeo isso não é executado de maneira clara, o que pode sugerir uma falta de organização por parte dos estudantes em evidenciar tal cena. E mesmo havendo diferenças na expressão dessas cenas, a professora-pesquisadora estimulou os alunos a desenvolverem cada uma das representações. "Desenvolver métodos de ensino que permitam aos alunos expor 
suas ideias" (CHASSOT, 2018, p. 116) permite que as aulas, sejam de maneiras expositivas ou lúdicas, despertem no educando o anseio em fazer descobertas e a produzir um conhecimento diversificado sobre os assuntos.

Nas representações das cenas 5 e 6, os estudantes expuseram as ligações químicas. $\mathrm{Na}$ cena 5 , a ligação covalente foi representada pela molécula $\mathrm{CH}_{4}$, em que os estudantes exprimiram o compartilhamento dos elétrons por meio da junção entre quatro elementos de hidrogênio e um de carbono. A ligação iônica foi expressa por meio das moléculas $\mathrm{CaCl}_{2}$ e $\mathrm{NaCl}$, de modo semelhante a ligação anterior em que os estudantes interagiram expressando cada elemento químico e sua ligação. A finalização do vídeo ocorreu por meio da saída dos elementos na festa, na seguinte ordem: hidrogênio, metais, ametais e gases nobres.

A produção do vídeo foi executada de maneira simples, com o uso de câmeras de celular e com o espaço do ambiente escolar como cenário de gravação. Os discentes estiveram envolvidos em todas as encenações e dividiram as tarefas de executar a gravação, a edição, o cenário de modo colaborativo. Uma característica presente na Aprendizagem Baseada em Projetos, que segundo Masson et al. (2012):

“[...] a importância especial do projeto, deve ser associada à singular mediação reali- 
zada, entre a criação individual, a intenção de reprodução, a habilidade de criação e o desenvolvimento, levando a uma realização pessoal abrangente entre as expectativas do novo e a consolidação de padrões no imaginário coletivo, numa busca contínua pela excelência da qualidade" (MASSON, et al., 2012, p.5).

O projeto desenvolvido teve como resultado a execução do produto "Química e Arte: Ensino além da sala de aula" que dispõem de todas as etapas, além de sugestões de como outros docentes e estudantes, na área do ensino de Química, possam executar um projeto semelhante.

\section{Considerações finais}

Os resultados do questionário mostraram como os estudantes apresentam uma visão benéfica sobre a execução de atividades artísticas e sua relação com a Química. Compreende-se que a utilização de tarefas como essas exige um planejamento e que sua efetivação depende em grande parte do envolvimento dos estudantes. Nesse caso, motivá-los é um fator primordial, ou seja, o docente além de expor a metodologia empregada para os estudantes, precisam dispor de maneira clara e objetiva todos os procedimentos necessários à efetivação do projeto. 
A análise do vídeo mostrou como as etapas para o seu desenvolvimento exigem organização, trabalho em equipe e envolvimento dos estudantes. O que foi objetivado e executado ao longo do trabalho da professorapesquisadora. $\mathrm{Na}$ atuação, os educandos estiveram presentes encenando de forma lúdica e proveitosa. A gravação e a edição, apesar de serem executadas com equipamentos simples, cumpriram com o objetivo de entregar o projeto.

O encarte, assim como o blog são ferramentas que além de estarem disponibilizadas de forma gratuita e sem restrição, permitem que seu acesso alcance ambos os públicos. No encarte, todas as orientações foram descritas com uma linguagem acessível e de fácil compreensão e no blog os menus e as postagens foram elaboradas com o intuito de mostrar as etapas de execução do projeto, um relato de experiência e dicas consideradas essenciais.

O produto foi elaborado diante da necessidade de um material que pudesse facilitar o ensino dos conteúdos de Química, de maneira didática e que permitisse que o estudante expressasse sua criatividade por meio de interações artísticas. E também com o intuito de expor um material que possibilitasse que estudantes do nível médio e docentes da área de ensino de Química possam elaborar um projeto semelhante. 


\section{Referências}

ALMEIDA, T; CASTRO, C; CAVALCANTI, E. A influência da linguagem audiovisual no ensino e na aprendizagem nas aulas de Química. Revista Tecnologias na Educação, ano 6, n. 11, dez. 2014.

BEHRENS, M.; JOSÉ. E. Aprendizagem por Projetos e os Contratos Didáticos. Revista Diálogo Educacional, v. 2, n. 3, p. 7796, jan./jun. 2001.

CHASSOT, A. Pra que(m) é útil o ensino? Editora UNIJUÍ, 4 ed, RS, 2018.

COSTA, F. Arte e Química: O uso do teatro como ferramenta interdisciplinar para tornar o ensino de Química mais atraente aos estudantes da primeira série do ensino médio. 2019. 89f. Dissertação (Mestrado Profissional em Ensino de Ciências e Matemática), Universidade Federal do Ceará, Ceará, 2019.

DEWEY, J. Experiência e educação; tradução de Anísio Teixeira. 2. ed. São Paulo, Ed. Nacional, 1976.

LEITE, L. Pedagogia de Projetos: Intervenção no Presente. Presença Pedagógica, Belo Horizonte, dez. 1994. Disponível em

$<$ https://edufisescolar.files.wordpress.co/2011/o3/pedagogiade-projetos-de-lc3bacia-alvarez.pdf $>$. Acesso em o1 de outubro de 2020.

MASSON, T; MIRANDA, L.; MUNHOZ-JR, A.; CASTANHEIRA, A. Metodologia de Ensino: Aprendizagem Baseada em Projetos (PBL). In: XI Congresso Brasileiro de Educação em Engenharia, Belém, PA, 03 a 06 set., 2012. 
NASCIMENTO, C. Química e Arte: Ensino além da sala de aula. 2020. 88f. Dissertação (Mestrado em Ensino de Química) - Instituto de Química, Universidade Federal do Rio de Janeiro, Rio de Janeiro, 2020.

PAIM, G. A história da borracha da Amazônia e a Química Orgânica: Produção de um vídeo didático-educativo para o ensino médio. 2020. 129f. Dissertação, Brasília, 2006.

PIETROCOLA, M. Curiosidade e Imaginação: Os caminhos do conhecimento as Ciências, nas Artes e no ensino. IN: CARVALHO, A. (Org.). Ensino de ciências: Unindo a pesquisa e a prática. São Paulo: Pioneira Thomsom Learning, 2004.

PIRES, E. A experiência audiovisual nos espaços educativos: possíveis interseções entre educação e comunicação. Educação e Pesquisa, São Paulo, v. 36, n.1, p. 281-295, jan./abr. 2010.

ROCHA, L.; JÚNIOR, C.; NEVES, M. Ciência e Arte: Possibilidades de Diálogo entre a Razão e a Emoção. Revista Valore, Volta Redonda, 3 ed. especial, p. 312-321, 2018.

SÁ, M.; FILHO, O. Possíveis Diálogos entre Arte e Ciência como forma de promover a Educação e Cultura Científicas. In: XVIII Encontro Nacional de Ensino de Química, Florianópolis, SC, Brasil - 25 a 28 de julho de 2016.

SILVA, J. L. et al. A utilização de vídeos didáticos nas aulas de Química no ensino médio para abordagem histórica e contextualizada do tema Vidros. Química Nova Escola, v. 34, n. 4, p. 189-200, nov. 2012.

STUMPENHORST, J. A nova revolução do professor: Práticas pedagógicas para uma nova revolução de alunos. Editora Vozes, RJ, 2018. 